\title{
BMJ Open Understanding the role of the immune system in adolescent idiopathic scoliosis: Immunometabolic CONnections to Scoliosis (ICONS) study protocol
}

\author{
M Constantine Samaan, ${ }^{1,2,3}$ Paul Missiuna, ${ }^{4}$ Devin Peterson, ${ }^{4}$ \\ Lehana Thabane $e^{3,5,6,7}$
}

To cite: Samaan MC,

Missiuna P, Peterson D, et al. Understanding the role of the immune system in adolescent idiopathic scoliosis: Immunometabolic CONnections to Scoliosis (ICONS) study protocol. BMJ Open 2016;6:e011812. doi:10.1136/bmjopen-2016011812

- Prepublication history for this paper is available online. To view these files please visit the journal online (http://dx.doi.org/10.1136/ bmjopen-2016-011812)

Received 8 March 2016 Revised 1 May 2016 Accepted 12 May 2016

For numbered affiliations see end of article.

Correspondence to Dr M Constantine Samaan; samaanc@mcmaster.ca

\section{ABSTRACT}

Introduction: Adolescent idiopathic scoliosis (AIS) affects up to $3 \%$ of children around the world. There is limited knowledge of AIS aetiopathogenesis, and this evidence is needed to develop new management strategies. Paraspinal muscle in AIS demonstrates evidence of differential fibrosis based on curve sidedness. Fibrosis is the hallmark of macrophagedriven inflammation and tissue remodelling, yet the mechanisms of fibrosis in paraspinal muscle in AIS are poorly understood.

Objectives: The primary objective of this study is to determine the influence of curve sidedness on paraspinal muscle inflammation. Secondary objectives include defining the mechanisms of macrophage homing to muscle, and determining musclemacrophage crosstalk in muscle fibrosis in AIS.

Methods and analysis: This is a cross-sectional study conducted in a tertiary paediatric centre in Hamilton, Ontario, Canada. We will recruit boys and girls, 10-17 years of age, who are having surgery to correct AIS. We will exclude children who have an active infection or are on immunosuppressive therapies within 2 weeks of surgery, smokers and pregnant girls. Paraspinal muscle biopsies will be obtained at the start of surgery. Also, blood and urine samples will be collected from participants, who will fill questionnaires about their lifestyle. Anthropometric measures will also be collected including height, weight, waist and hip circumferences.

Ethics and dissemination: This study has received ethics authorisation by the institutional review board. This work will be published in peer-reviewed journals and will be presented in oral and poster formats at scientific meetings.

Discussion: This study will explore the mechanisms of paraspinal muscle inflammation, remodelling and fibrosis in AIS. This will help identify pathways and molecules as potential therapeutic targets to treat and prevent AIS. It may also yield markers that predict scoliosis progression and response to treatment in these children.

\section{Strengths and limitations of this study}

- This is the first study to determine the mechanisms of inflammation and its effect of paraspinal muscle remodelling and fibrosis in AIS.

- This study will also shed light on immune cell phenotype differences in paraspinal muscle on both sides of the scoliotic curve, and how this then drives immune-muscle crosstalk in AIS.

- Owing to the cross-sectional nature of the study, it will not be possible to determine immune cell phenotype in muscle is a cause or effect of spinal curving.

- As samples are collected at the maximal points of convexity and concavity, potential changes in other parts of the paraspinal muscle will not be studied.

\section{INTRODUCTION}

Idiopathic scoliosis is a three-dimensional deformity of the spine that occurs in up to $3 \%$ of children globally. ${ }^{1}$ Adolescent idiopathic scoliosis (AIS) is the most common form $^{12}$ and in $80 \%$ of cases occurs in girls. ${ }^{3}$

AIS has potential implications for health across the lifespan, including pain, mobility problems, pulmonary hypertension and psychological health issues. While some of these complications have beens inconsistently reported, their occurrence places a heavy burden on the child, and some do not improve with treatment. ${ }^{4-6}$ It is a challenge to predict which child will develop AIS, and who is at risk of curve progression, which limits the development of precise therapies. The potential risk factors for progression of the scoliotic curve include curves with Cobb angle $\geq 30^{\circ}$, pubertal growth spurt, premenarchal girls, a right thoracic curve in girls and left lumbar curve in boys. ${ }^{17}$ 
Current treatment options depend on the severity of the scoliotic curve. In patients who are still growing with a Cobb angle $<25^{\circ}$, observation is the mainstay of therapy. In cases with significant curvature (Cobb angle $25-40^{\circ}$ ) or with worsening of the curve, patients may require bracing to help control progression, but this does not reduce the severity of the curve. ${ }^{8-13}$ In those who have completed growth or are still growing with significant curves (Cobb angle $45^{\circ}$ or higher), surgery is often undertaken to halt curve progression and induce partial correction. ${ }^{14-18}$ Bracing and surgical complications, although rare, are significant especially neurological complications in combined anterior and posterior surgical procedures. ${ }^{19} 20$

The mechanisms driving the initiation and propagation of the scoliotic curves are incompletely understood, and there is a paucity of models that can improve insights into the genesis of AIS. Animal models do not have the same spinal architecture of humans. Some models rely on chemical induction of scoliosis, so the faithful replication of aetiopathogenesis of AIS in these models is not possible. ${ }^{21}{ }^{22}$ The prevalence of AIS, potential comorbidities, treatment-related complications, the lack of a unifying mechanism and the dearth of models to provide mechanistic insights into AIS occurrence make this disease a significant challenge to solve. Understanding the aetiopathogenesis of AIS continues to rely on studying humans as the best model of their disease.

Defining the mechanisms driving AIS will help the development of precise diagnostic, therapeutic and prevention strategies, which will likely improve outcomes.

Potential mechanisms driving AIS aetiopathogenesis: It is clear that AIS is a polygenic disease with genetic, epigenetic, nervous system, hormonal/metabolic, biochemical, musculoskeletal, environmental and possible lifestyle factors contributing to its genesis. ${ }^{23}{ }^{24}$ Regardless of its cause, abnormalities of vertebral growth plates are a final destination for many proposed mechanisms that drive AIS. Still, there are many unanswered questions regarding the mechanisms involved in the development and progression of AIS.

Genetic factors: AIS is more common in families with a history of the disease, but there is no definite mode of inheritance. The main hurdles to identifying genes of AIS pathogenesis are the heterogeneity of genotypic and phenotypic definitions of cases, and relatively small sample sizes included in genetic studies. ${ }^{25}$

It is likely that many genes of minor effect contribute to the development of AIS. Twin studies have been inconsistent in showing increased concordance in monozygotic and dizygotic twins. ${ }^{26-30}$ This inconsistency suggests that other factors, including environmental and epigenetic elements, contribute to AIS with a given genetic background.

Gene linkage studies suggest that genetic factors influence the development of AIS, with loci so far on chromosomes $1,3,5,6,7,8,9,11,12,16,17,18$ and $19 .{ }^{25} 293132$
Several candidate genes have been linked to AIS, but confirmation of these associations remains inconsistent and requires larger replication studies. ${ }^{33-42}$ A two-phase model for the development of AIS has been proposed. Under this model, a set of genetic factors initiate the development of the curve, while another set determines curve progression. These sets of genes may overlap in their effects and may be influenced by the environment. ${ }^{43}$

Importantly, genome-wide association studies (GWAS) have implicated new genes, with one study creating a list of markers that are predictive of curve progression. ${ }^{44}$

A recent GWAS reported the association of a gene expressed in the dorsal spinal cord, skeletal muscle and somatosensory neurons with AIS. Ladybird homeobox 1 (LBX1) is involved in muscle precursor and neuronal cell development and migration. ${ }^{45-47}$

A microduplication of the genomic region where LBX1 gene resides (10q24.31) was associated with scoliosis and myopathy. ${ }^{48}$ Further studies are needed to explore the mechanistic details of the role of LBX1 in AIS.

Epigenetics: Epigenetics refer to the phenomenon of production of different phenotypes due to changes in the expression of a gene rather than its sequence. ${ }^{49}$ Epigenetics is one of the mechanisms driving many noncommunicable diseases due to exposure to an adverse intrauterine environment, ${ }^{50}$ but the role of epigenetics in AIS requires further study. ${ }^{23}$

Environmental and lifestyle factors: Sporadic reports link low body mass index (BMI) and diet (eg, calcium intake) with the prevalence of AIS. Inadequate calcium intake during the peripubertal period might result in poor bone mineralisation with accelerated bone growth. ${ }^{51-54}$

There is controversy as to whether girls with AIS have different body composition compared with girls with no AIS. Some studies have reported that BMI and fat mass are lower in AIS, but this has not been a consistent finding. ${ }^{52-54}$ The differences in BMI and adiposity may affect spinal development and skeletal maturation, and their role in AIS is unknown. Also, lower physical activity has been studied as an association of AIS, and the speculation is that this is related to a proprioception defect. ${ }^{51}$ Later age of menarche has been associated with more risk of AIS, and the risk is reduced for those who live closer to the equator. ${ }^{55}$ Systematic studies of the role of environmental factors in AIS are needed.

The nervous system: As patients with several neurological syndromes have scoliosis, there has been significant focus on defining neurological factors contributing to AIS ${ }^{56-58}$ In addition, defects in central control and processing of information have been proposed to be associated with AIS, although their role in the development and propagation of AIS remains under investigation.

Anatomical abnormalities involving spine, midbrain, pons, medulla, vestibular and hindbrain regions have 
been reported in AIS. ${ }^{59-61}$ Differences in brain volume, internal capsule and corpus callosum were also reported. ${ }^{62-64}$ How these differences drive AIS is a mystery.

Neurophysiological mechanisms have also been reported in AIS, including abnormal proprioception, oculovestibular dysfunction, lateral gaze palsy, dynamic balance problems, postural imbalance and somatosensory disequilibrium. ${ }^{65-70}$ There have also been reports of enhanced electromyographic activity of the convex side of the spine. ${ }^{71}$

These phenomena led to the hypothesis that a combination of abnormal spinal growth patterns and neuromuscular and tissue remodelling is implicated in AIS. ${ }^{72}$ Posture is determined by sensory input from visual, vestibular and proprioception neural pathways, coupled with motor output. As a first step, postural disequilibrium due to defects in the neuromuscular system leads to the development of small spinal curves. With ongoing spinal growth, a second step involves biomechanical and neurological factors that drive the progression of the curve. ${ }^{72}$ With the establishment of scoliosis, secondary geometric and morphological changes emerge. ${ }^{73-75}$

Hormones and metabolic dysfunction: Studies have produced mixed results on the association of several biomarkers, their receptors and gene variants with AIS. Some of the data have suggested that growth hormone $(\mathrm{GH}),{ }^{76} 77$ calmodulin, ${ }^{78}$ melatonin ${ }^{42}{ }^{78-83}$ and leptin ${ }^{84} 86$ may have a role in AIS.

Melatonin deficiency, triggered by pinealectomy, was shown to cause scoliosis, ${ }^{87-89}$ and melatonin levels were reported to be reduced in patients with AIS. ${ }^{90}$ Both findings were not replicated in other studies that used pinealectomy or light stimulation to suppress melatonin in different models, including primates. ${ }^{8391} 92$ One study suggested impairment in the melatonin signalling pathway in primary osteoblasts from patients with AIS. ${ }^{93}$ It has been proposed that initial spinal imbalance is sustained by biochemical, postural and melatonin signalling pathways that contribute to the development of scoliosis. ${ }^{94}$ Further research is needed to define the potential role of melatonin in AIS.

Calmodulin is a regulator of contractile properties of muscle, and its increased levels may lead to altered paraspinal muscle activity and progression of the scoliotic curve. This hypothesis is supported by the fact that calmodulin is asymmetrically distributed across the paraspinal muscles of patients with AIS. ${ }^{78}$

Leptin has also been implicated in the genesis of AIS. ${ }^{84} 86$ The 'leptin-hypothalamic-sympathetic nervous system theory' proposes that asymmetrical hypothalamic upregulation of leptin signalling leads to an asymmetrical activation of the sympathetic nervous system that may be associated with upregulation of $\mathrm{GH} /$ insulin-like growth factor 1 (IGF-1) axis. ${ }^{95}$

Since the sympathetic nervous system regulates the growth of the axial skeleton, the resulting asymmetrical vertebral growth plates may affect the progression of AIS, while the somatic nervous system may be involved in the initiation of the curve by the failure of mechanisms that maintain posture..$^{95} 98$

Biomechanical factors: The human spine has natural kyphotic curves at thoracic and sacral regions, and lordotic curves at cervical and lumbar regions. One consistent anomaly in AIS is the shape abnormality in the sagittal plane. ${ }^{99}$ A large study that evaluated children for scoliosis demonstrated that lordosis was always present prior to the development of thoracic AIS. ${ }^{100}$ One potential hypothesis that may explain the progression of the spinal curve in AIS is that patients with AIS are taller than controls, and this is coupled with the fact that girls have more slender spines than boys. ${ }^{99}$ This makes the spine in girls more likely to buckle under force, and this is maximised during periods of rapid spinal growth including puberty. Increased compression force on the concave side may reduce spinal growth, while reduced loading on the convex side may accelerate growth. ${ }^{99} 101$ Another important study that evaluated cadaveric idiopathic scoliosis demonstrated that the primary abnormality is lordosis with anterior vertebral wedging. This leads to biomechanical instability, and compensatory rotation and scoliosis. ${ }^{102}$

\section{Paraspinal muscle metabolism in AIS}

The fibre composition of paraspinal muscle in AIS has been studied, and while the results are inconsistent, the prevailing view is that type I fibres are more prevalent on convex side of the curve. Type II fibres are increased or reduced on the concave side, but they were increased on the convex side in one study. ${ }^{103-109}$

Other abnormalities noted in muscle include increased intracellular calcium, reduced zinc, ${ }^{109}$ increased glucocorticoid receptors on the convex side, ${ }^{111}$ reduced RNA activity on the concave side and increased protein synthesis on the convex side. ${ }^{112}$ Muscle enzymes seem equal with minor exceptions. ${ }^{113}$

\section{Skeletal muscle-immune crosstalk: a novel paradigm in potential pathogenesis of AIS}

While the literature hints at muscle phenotype as a secondary phenomenon in scoliosis, it is a difficult conclusion to establish.

One important consideration is that the diagnosis of AIS is taken to be the time of presentation. However, scoliosis would have evolved over an undefined period before the diagnosis, making longitudinal studies starting at inception a challenge. Therefore, muscle phenotype may drive or be driven by scoliosis. In addition, it is not feasible to obtain repeated muscle biopsies to assess muscle changes in scoliosis, as this is an invasive procedure.

All studies that have examined muscle pathology in AIS have done so in a cross-sectional fashion due to these limitations. ${ }^{22} 114115$ Animal models used to study this disease have relied on surgically or chemically 
induced scoliosis, which may not faithfully recapitulate the events in patients and requires specific expertise especially when using big animals (eg, chicken). ${ }^{114}$

Recent evidence suggests that while paraspinal muscle on both sides of the spinal curve has increased fibrosis, muscle on the concave side of the spine demonstrated more enhanced fibrosis and fatty involution compared with that on the concave side. ${ }^{115}$ These findings were taken to suggest a myopathic process based on finding central core lesions in muscle. Importantly, fibrosis is the hallmark of immune cell-tissue interaction to remodel tissues and restore homeostasis. ${ }^{116} 117$

\section{Innate immunity and fibrosis in AIS}

The innate immune system is the initial line of defence against environmental threats. ${ }^{118}$ Components of the innate immune system include cells (monocytes, neutrophils, basophils, eosinophils, natural killer cells, dendritic cells, and mast cells) and receptors including nucleotide-binding oligomerisation domain (NOD) proteins and Toll-like receptors (TLRs) and complement proteins. ${ }^{119-121}$ While acute activation in muscle injury results in a controlled remodelling response mediated by neutrophils and macrophages, chronic activation and low-grade inflammation can lead to dysregulation of tissue remodelling and fibrosis. ${ }^{116} 122$

Circulating monocytes are attracted to different tissues in response to chemokines. Monocytes sense the muscle microenvironment and, guided by tissue cues, differentiate to macrophages. ${ }^{123}$ There are two main types of macrophages. Inflammatory or M1 macrophages originate from bone marrow-derived monocytes that enter the injured tissue, and produce pro-inflammatory cytokines and are detected in muscle. ${ }^{124}$ Resident or M2 macrophages are present in tissues under physiological conditions and help with tissue homeostasis and remodelling. ${ }^{125}$ The imbalance between anti-inflammatory actions of M2 and inflammatory responses by M1 macrophages is a fundamental driver of the effects of inflammation on muscle phenotype. This M1 and M2 paradigm is a rather simplistic view of macrophage phenotype, and there are several intermediate phenotypes driven by tissue demands. ${ }^{126} 127$ One possibility is that in AIS, muscle inflammation is an acute-on-chronic process, whereby repeated cycles of tissue injury related to the progression of the scoliotic curve may lead to concomitant inflammation and fibrosis. This is supported by paraspinal muscles demonstration of simultaneous atrophy and hypertrophy, indicating that there is ongoing activity to remodel muscle. ${ }^{115}$ Muscle tissue injury may be the primary initiating event or the result of spinal curvature.

Recent evidence has strengthened the role of macrophages in muscle fibrosis in a chronic muscle disease, Duchenne muscular dystrophy. ${ }^{128}$ Acute muscle injury is characterised by three important responses: (1) expansion of satellite cells (muscle stem cells), (2) infiltration of inflammatory M1 macrophages and (3) expansion of resident mesenchymal cells (fibro/adipogenic progenitor cells, FAPs). The latter two mechanisms regulate myogenesis, whereby the expansion of FAPs in acute injury is followed by an apoptotic response to regulate FAP mass; tumour necrosis factor $\alpha(\mathrm{TNF} \alpha)$, a prototypical inflammatory cytokine, is secreted by infiltrating inflammatory macrophages and drives this response. This allows limited FAP expansion and regulates tissue remodelling to restore normal tissue function. ${ }^{128}$

On the other hand, chronic or repeated muscle injury (which may be a primary or secondary event in AIS) triggers a tissue repair response. This response is characterised by expansion of progeneration (M2) macrophages, activation of FAPs and the production by M2 macrophages of transforming growth factor $\beta 1$ (TGF $\beta 1$ ), which inhibits $\mathrm{TNF} \alpha$ and allows FAP expansion. This is associated with enhanced fibrosis and extracellular matrix deposition in muscle. ${ }^{128}$ Therefore, the shift from pro-myogenic to profibrotic muscle response is driven by macrophage population differences; whether this translates to AIS is unclear.

In addition, other innate and adaptive immune cells are likely to play a role in muscle Immunometabolism, but limited data exist as to their role in AIS.

Immune cells and the chemokine(s) that attract them to paraspinal muscle in AIS have not been studied. However, they may contribute to the initiation or propagation (or both) of the spinal curve in AIS by influencing muscle remodelling. In addition, muscle-bone-cartilage-disc-immune crosstalk at the interphase of these tissues is critically important to tissue metabolism and health $^{129}$ but has not been studied in AIS. Understanding the role of the immune system in muscle inflammation, metabolism and fibrosis in AIS is the objective of the proposed study.

The role of skeletal muscle inflammation and fibrosis in the causation of AIS is not completely understood. It is imperative to delineate the role of immune cells in muscle in AIS, as this may help define targeted therapies to muscle immune cells, and define biomarkers of scoliosis initiation, progression and response to therapy.

The Immunometabolic CONnections to Scoliosis (ICONS) study was designed to investigate paraspinal muscle-immune crosstalk in AIS, and is focused primarily on understanding the role of the macrophage in AIS.

\section{Research question}

In adolescents with AIS, does paraspinal muscle on the concave side of the scoliotic curve, compared with paraspinal muscle on the convex side, have enhanced anti-inflammatory macrophage infiltration? If so, is this associated with FAP expansion and fibrosis?

\section{Objectives}

Primary: To quantify macrophages and muscle inflammation in paraspinal muscle from concave and convex sides of the scoliotic curve.

Secondary:

1. Profile chemokines in paraspinal muscle from concave and convex sides of the scoliotic curve. 
2. Assess the role of FAP in muscle fibrosis in AIS.

Hypothesis: In adolescents with AIS, enhanced antiinflammatory macrophage infiltration of paraspinal muscle on the concave side, compared with the convex side of the curve, drives FAP expansion and differential fibrosis.

\section{Methods and study procedures}

Study design

This is a cross-sectional study. The participants will be recruited from Pediatric Orthopedic clinical services at McMaster Children's Hospital, a tertiary paediatric care centre in Hamilton, Ontario, Canada. The study procedures are described in figure 1.

\section{Cohort characteristics}

Inclusion criteria: We will include boys and girls, 10-17 years of age with a diagnosis of AIS confirmed on clinical and radiological grounds, and who have been informed by their team that they require and have agreed to undergo spinal surgery. We will include lean
(BMI centile below 85th) and overweight/obese (BMI centile $\geq 85$ th) who are free from infection for 15 days before sample collection.

Exclusion criteria: We will exclude patients with scoliosis related to other causes, including congenital scoliosis, neuromuscular disorders, metabolic disorders, skeletal dysplasia and syndromes. We will also exclude those on certain medications used within 15 days prior to sample collection (including high-dose steroids, immunosuppressive therapy and anti-thrombotic medications). We will also exclude those with active bacterial, viral or fungal infections, and chronic inflammatory diseases including autoimmune disease (systemic lupus erythematosus, juvenile idiopathic arthritis, dermatomyositis). We will also exclude smokers, pregnant girls and those who are unable or unwilling to provide consent.

\section{Recruitment and consents}

The ICONS study will recruit patients who have been deemed eligible for scoliosis surgery. The healthcare provider will ask permission from potential participants

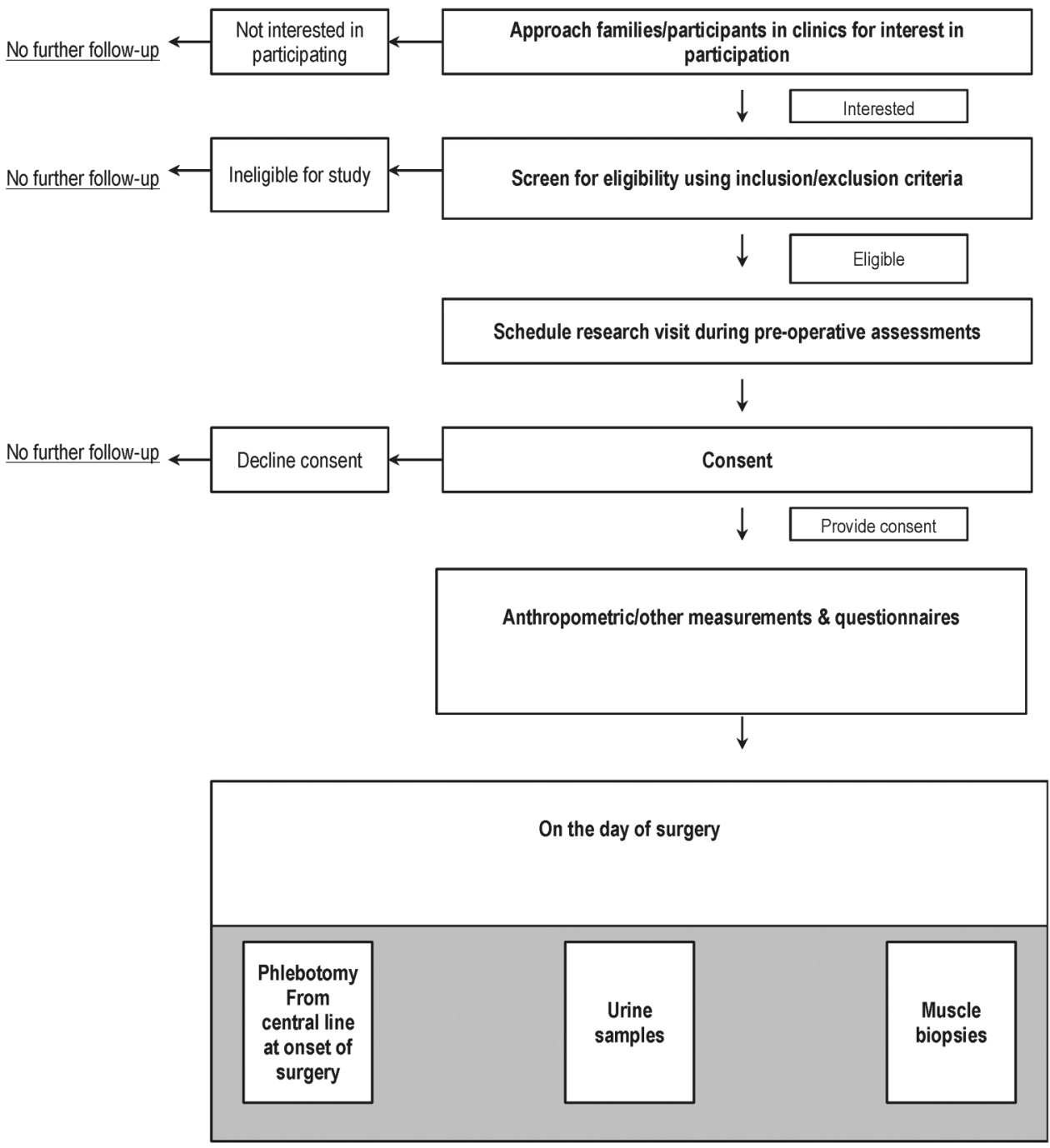

Figure 1 ICONS study flow diagram. ICONS, Immunometabolic CONnections to Scoliosis study. 
to be approached by the study team. If patients and parents agree, the study team will meet the participants on the day of their preoperative evaluation to introduce the study and answer questions.

If the family and participant agree to participate, consent forms will be signed. The consent forms include those for parents and assent forms for children aged between 10 and 15 years. For those aged 16 years or older, the participants will sign their consents. Separate consent forms for genetic (DNA) testing are completed. The participants are assigned unique identifying numbers to protect confidentiality and data are anonymised shortly after collection.

\section{Questionnaires}

After consent procedures are completed, study questionnaires are provided to the participants and their families.

The study will collect sociodemographic and clinical data including age, gender, grade in school, parental education, religion, ethnicity, history of medical or surgical problems, birth history, family income, social history and family history of medical problems.

Regarding dietary information, the intake of different food items will be documented using a dietary questionnaire modified from the Adolescent Food Frequency Questionnaire. ${ }^{130}{ }^{132}$ Reported physical activity will be measured using the Habitual Activity Estimation Scale (HAES) Questionnaire. ${ }^{133}$ Sleep will be measured using the Chevrin Sleep Questionnaire. ${ }^{134}$ We will also enquire about mental health by asking participants or parents to fill a questionnaire reporting mental health problems. ${ }^{135}$ Neighbourhood walkability will be determined using the Neighborhood Environment Walkability Scale (NEWS) Questionnaire. $^{136}$

\section{Anthropometric and clinical measurements}

The participants will have their height measured closest to $0.1 \mathrm{~cm}$ using a stadiometer, weight to closest $0.1 \mathrm{~kg}$ using weighing scale, and BMI in $\mathrm{kg} / \mathrm{m}^{2}$ will be calculated from height and weight and BMI centile determined from Centers for Disease Control (CDC) growth charts. The waist circumference and hip circumference will be measured using a spring-loaded measuring tape closest to $0.1 \mathrm{~cm}$. Puberty will be assessed using drawings describing Tanner staging for girls 8 years or older, and external genitalia for boys 9 years and older. ${ }^{137}$

Sitting systolic and diastolic blood pressure (BP) will be measured using automated BP monitor, and pulse rate is measured using the same device. Body fat percentage is measured using Tanita body fat monitor for children (Tanita Corporation, Illinois, USA), and grip strength will be tested using a dynamometer.

\section{Biological samples}

All samples will be obtained on the day of surgery after an overnight fast of $8-10$ hours.
Blood

Blood samples are obtained after patients are anaesthetised and central lines are in place to permit blood sampling. We will be collecting serum and plasma samples as well as buffy coat for DNA studies. PAX RNA whole blood samples are also collected for RNA studies. Samples will be aliquoted to cryovials and stored at $-80^{\circ}$ $\mathrm{C}$ until further use.

\section{Urine}

Urine samples will be obtained using $90 \mathrm{~mL}$ urine containers after urinary catheterisation for the surgical procedure. Urine is aliquoted to cryovials and stored at $-80^{\circ} \mathrm{C}$ until further use.

\section{Tissue sampling and processing}

Paraspinal muscle (erector spinae) samples will be collected shortly after starting the surgical procedure for correction of scoliosis. The points of sampling include samples from the apex (maximal area of convexity) of the spinal curve, matched with a biopsy from the area of maximal concavity on the opposite side of the spinal curve.

Two important procedures are applied during sample collection that will ensure fidelity of immune cell phenotype. First, we will collect the samples before epinephrine injections, used to control bleeding during surgery, as it is known that adrenergic stimuli may change macrophage responses. We will also avoid cauterised areas for tissue sampling.

The muscle samples will be cleaned from blood by drying with gauze, and connective tissue is separated from samples. Tissue samples are then divided into five pieces, and four pieces will be snap frozen immediately in liquid nitrogen and transferred to $-80^{\circ} \mathrm{C}$ freezer for storage. One piece will be formalin fixed and paraffin embedded until further processing.

\section{Experimental work details}

Primary objective: determine the influence of curve

sidedness on paraspinal muscle inflammation

Muscle macrophage content will be profiled using CD68 quantitative real-time PCR (qRT-PCR), western blot and immunohistochemistry (IHC). ${ }^{124} 138$

For qRT-PCR, muscle tissue (25-50 mg) will be chipped and powdered, and then added to Trizol reagent. The tissue will be homogenised, and RNA isolation will take place using RNeasy Mini Kit (Qiagen).

In total, $1 \mu \mathrm{g}$ of RNA will be used to generate complementary DNA (cDNA) using SuperScript III Reverse Transcriptase Kit (Invitrogen, Carlsbad, California, USA). qRT-PCR will be completed using TaqMan assay primer/probe mixes (Applied Biosystems) as we previously described. ${ }^{124} 139$ Western blot and IHC will be performed as described previously by our group. ${ }^{124} 138139$

The full characterisation of macrophage phenotype will be determined by testing markers of inflammatory macrophages, including cluster of differentiation-11c 
(CD11c), arginase II and C-C chemokine receptor 2 (CCR2). Anti-inflammatory macrophages will be detected by using CD206, TGF 31 and CD301 using qRT-PCR, western blot and IHC co-staining methods. ${ }^{140}$ We will use Nikon Eclipse 90i microscope for imaging, and analyse images to determine macrophage content using NIS Elements 64 bit 3.22.11 software (Nikon Inc, Melville, NY, USA). ${ }^{138} 141$

To profile muscle inflammation, we will perform qRT-PCR using TaqMan assay primer/probe mixes (Applied Biosystems) on cDNA synthesised from RNA from muscle.

We will test the gene expression of pro-inflammatory cytokines including TNF $\alpha$, interleukin $1 \beta$ (IL-1 $\beta$ ), IL-6 and interferon $\gamma$ (IFN $\gamma)$. Anti-inflammatory cytokines measured include IL-10 and IL-1 receptor antagonist (IL-1Ra).

We will also measure cytokines in lysates from muscle (TNF $\alpha$, IL-1 $\beta$, IL-6, IFN $\gamma$, IL-10, IL-1Ra) using Bio-Plex assays (Bio-Rad) as we previously reported. ${ }^{138}$

Activation of inflammatory pathways responsible for cytokine and chemokine production will be tested using western blot, including c-Jun-N-terminal kinase (JNK), extracellular signal-regulated kinase (ERK), p38 mitogen-activated protein kinase (p38MAPK) and nuclear factor $\kappa \mathrm{B}(\mathrm{NF \kappa \textrm {B }})$ pathways (cell signalling). ${ }^{139}$

Total and phosphorylated (activated) versions of the molecules will be quantified and reported as a ratio of phosphorylated/total protein. Glyceraldehyde-3phosphate dehydrogenase (GAPDH) will be used as a loading control. ${ }^{139}$

\section{Secondary objectives}

Profile chemokines in paraspinal muscle from concave and convex sides of the scoliotic curve

As chemokines drive macrophage migration to muscle, there is a need to determine the chemokines driving macrophage infiltration to muscle in AIS. We will assess the gene expression of CCL2, CCL3, CCL5, macrophage colony-stimulating factor (M-CSF), granulocyte-monocyte colony-stimulating factor (GM-CSF), and chemokine (C-C) ligand 20 (CCL20), which accounts for most muscle chemokinetic activity.

Chemokine protein content (CCL2, CCL3, CCL5, MCSF, GM-CSF, CCL20) will be assessed using Bio-Plex assays (Bio-Rad) as we previously reported. ${ }^{138}$

\section{Assess the role of FAP in muscle fibrosis in AIS}

The experimental design of this part is described in figure 2. We will generate macrophages and evaluate inflammatory (M1) and anti-inflammatory (M2) effects on FAPs. We will isolate FAPs from paraspinal muscle using $\mathrm{CD} 15^{+} \mathrm{PDGFR} \alpha^{+} \mathrm{CD} 56^{-}$markers after collagenase digestion by flow cytometry. ${ }^{142}$

To generate macrophages, we will differentiate THP-1 human monocyte cell line to macrophages (24-hour incubation with $150 \mathrm{nM}$ phorbol 12-myristate 13-acetate (PMA), followed by 24-hour incubation in Roswell Park
Memorial Institute (RPMI) medium). Macrophages will then be polarised to M1 macrophages $(20 \mathrm{ng} / \mathrm{mL} \mathrm{IFN} \gamma$ $+10 \mathrm{pg} / \mathrm{mL}$ lipopolysaccharide (LPS)). Polarisation to M2 will be done by incubating cells in $20 \mathrm{ng} / \mathrm{mL}$ IL- 4 $+20 \mathrm{ng} / \mathrm{mL}$ IL-13). ${ }^{143}$ We will collect the medium in which M1 and M2 cells are growing in. This conditioned medium from M1 (CMM1) and M2 (CMM2) will be used in this set of experiments. To determine if inflammatory (M1) macrophages produce factors that reduce FAP proliferation and differentiation, we will treat FAPs with CMM1 for 24 hours. We will then measure FAP proliferation with bromodeoxyuridine (BrdU) incorporation assay, differentiation to adipocytes using oil red $\mathrm{O}$ staining and differentiation to fibroblasts using gene expression and western blot of ER-TR7, fibroblastspecific protein 1 (FSP-1) and $\alpha$ smooth muscle actin. We will also test FAPs for apoptosis by performing terminal deoxynucleotidyl transferase-mediated deoxyuridine triphosphate nick-end labeling (TUNEL) assay using TiterTACS in situ kits (R\&D Systems). We will then measure CMM1 cytokines including TNF $\alpha$ using ELISA, and use TNF $\alpha$ neutraliser adalimumab, and repeat the FAP treatment. ${ }^{144}$ In addition, we will treat FAPs with TNF $\alpha$ receptor antagonist (R-7050; Santa Cruz) ${ }^{145}$ and repeat the experiments.

To determine if anti-inflammatory (M2) macrophages produce factors that enhance FAP proliferation and differentiation, we will treat FAPs with CMM2 for 24 hours. We will then measure FAP proliferation with BrdU incorporation assay, differentiation to adipocytes using oil red $\mathrm{O}$ staining and differentiation to fibroblasts using gene expression and western blot of ER-TR7, FSP-1 and $\alpha$ smooth muscle actin, and apoptosis by performing TUNEL assay. We will then measure CMM2 cytokines including TGF $\beta$, and then use TGF $\beta$ neutralising antibodies and test FAP proliferation and differentiation. We will also treat FAPs with TGF $\beta$ receptor antagonist (LY2157299; Eli Lilly), ${ }^{146}$ and repeat the FAP treatment with CMM2.

\section{Statistical analysis}

Outcome variables will be summarised using descriptive summary measures expressed as mean (SD) or median (minimum-maximum) for continuous variables, and number (\%) for categorical variables. Data will be checked for normality using Kolmogorov-Smirnov test, and $\log$ transformed if not normally distributed. We will test differences in sociodemographic and clinical data between groups using $\chi^{2}$ tests for categorical variables and t-test or Kruskal-Wallis tests for continuous variables depending on the distribution. Statistical analysis of qRT-PCR experiments will be done using $\Delta \Delta \mathrm{CT}$. $^{124}$ For ELISA, standard curves will be generated and cytokines normalised to total protein content of the sample and reported as $\mathrm{pg} / \mu \mathrm{L} / \mu \mathrm{g}$ protein. ${ }^{138}$ For western blots, we will measure the total and phosphorylated protein and generate a ratio of total/phosphoprotein for comparisons. $^{139}$ 


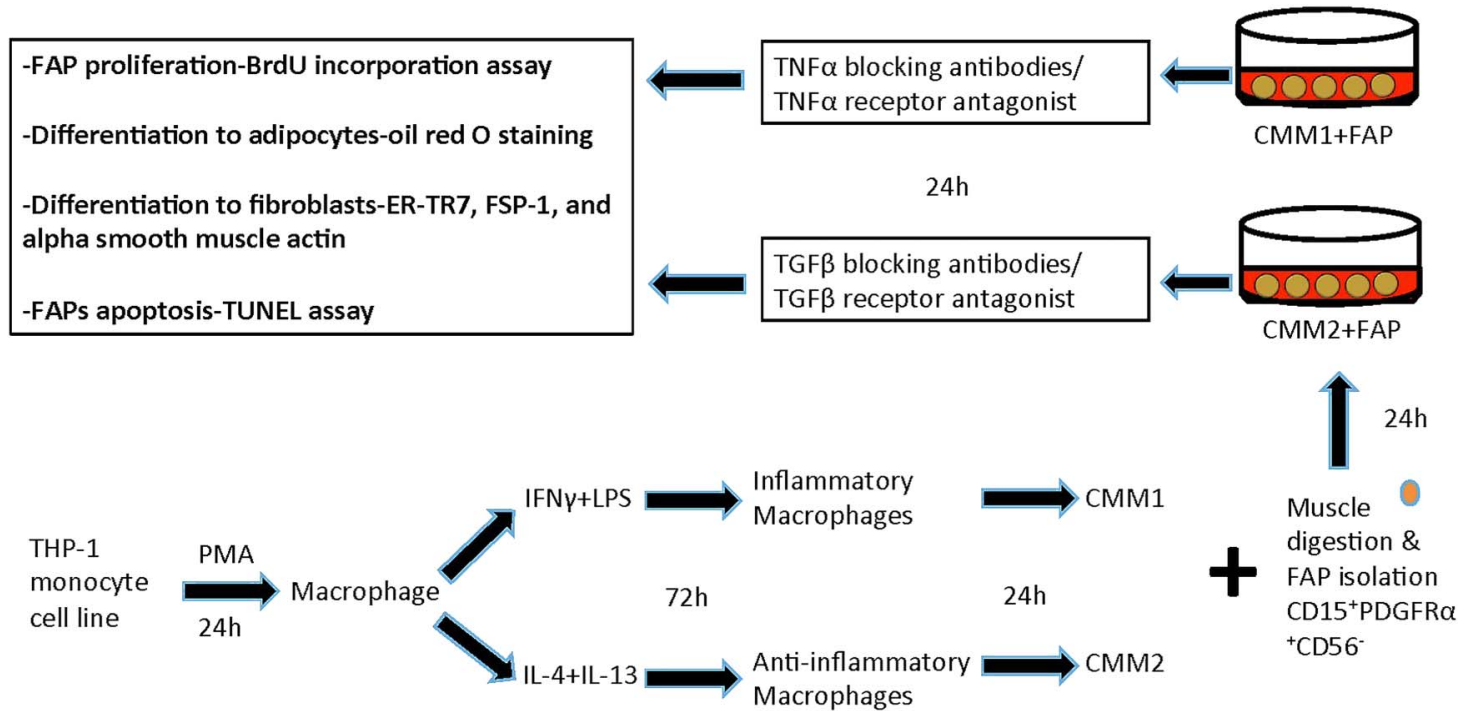

Figure 2 Testing macrophage-muscle crosstalk in adolescent idiopathic scoliosis (AIS). THP-1 monocyte cell line is treated with $150 \mathrm{nM}$ phorbol 12-myristate 13-acetate (PMA) for 24 hours to generate macrophages. Macrophages are treated with $20 \mathrm{ng} / \mathrm{mL}$ interferon $\gamma(\mathrm{IFN} \gamma)+10 \mathrm{pg} / \mathrm{mL}$ lipopolysaccharide (LPS) to generate inflammatory macrophages, and $20 \mathrm{ng} / \mathrm{mL}$ interleukin 4 (IL-4)+20 ng/mL IL-13 to generate anti-inflammatory macrophages. The medium the cells are growing in is called conditioned medium (CM) for inflammatory (CMM1) and anti-inflammatory (CMM2) macrophages. To generate fibro/adipogenic progenitors (FAPs), muscle will be digested with collagenase, and FAPs will be plated into 12 well plates. We will then add CMM1 and CMM2 to FAPs, and then test FAP proliferation, differentiation to adipocytes and fibroblasts, and apoptosis. BrdU, bromodeoxyuridine; FSP-1, fibroblast-specific protein 1; TGF $\beta$, transforming growth factor $\beta$; TNF $\alpha$, tumour necrosis factor $\alpha$; TUNEL, terminal deoxynucleotidyl transferase-mediated deoxyuridine triphosphate nick-end labelling.

For IHC, macrophages will be counted manually at $\times 400$ magnification, and the number of macrophages is normalised to the section area. The researcher counting the cells will be blinded to the experimental group allocations as we previously reported. ${ }^{138}$

For human samples, all analyses will be performed using regression analyses to pool and compare the groups adjusted for age, sex, BMI, ethnicity and fitness. For in vitro studies, data will be analysed using t-test.

The results will be reported as estimates of the difference, corresponding 95\% CIs and associated $\mathrm{p}$ values. Alpha is set at 0.05, adjusted using Bonferroni approach for multiple analyses. All analyses will be performed using SAS 9.2 (Cary, North Carolina, USA).

Sample size: For sample size calculations for the full study, as macrophage phenotype evaluation in paraspinal muscle has not been done in AIS before, power calculation is difficult. We aim to recruit 120 patients based on sample size calculations according to Norman and Streiner, ${ }^{47}$ whereby 10 patients are needed per marker studied. We plan to approach 200 patients, and assuming $80 \%$ recruitment rate, and $20 \%$ attrition, with one patient being evaluated weekly for surgery and 40 scoliosis surgeries per year at our institution, we plan to complete patient recruitment over 60 months for the full study.

\section{DISCUSSION}

Previous research has demonstrated the presence of fibrosis in paraspinal muscle in AIS. ${ }^{115}$ The immune system is one of the major players in muscle tissue remodelling via inflammation, yet this has not been fully studied in AIS.

This work will focus on understanding the mechanisms driving immune-muscle crosstalk in AIS, and the contribution of FAPs to muscle fibrosis. This work will aid the development of anti-inflammatory and antifibrotic therapies to help retain muscle strength, reduce pain and delay or prevent the development of the scoliotic curve. This study may also reveal muscle-specific biomarkers that predict initiation and progression of the scoliotic curve, response to therapy or the development of complications.

\section{Author affiliations}

${ }^{1}$ Department of Pediatrics, McMaster University, Hamilton, Ontario, Canada

${ }^{2}$ Division of Pediatric Endocrinology, McMaster Children's Hospital, Hamilton, Ontario, Canada

${ }^{3}$ Department of Clinical Epidemiology \& Biostatistics, McMaster University, Hamilton, Ontario, Canada

${ }^{4}$ Division of Orthopedics, Department of Surgery, McMaster University, Hamilton, Ontario, Canada

${ }^{5}$ Department of Anesthesia, McMaster University, Hamilton, Ontario, Canada

${ }^{6}$ Centre for Evaluation of Medicines, Hamilton, Ontario, Canada

${ }^{7}$ Biostatistics unit, St Joseph's Healthcare Hamilton, Hamilton, Ontario,

Canada

Contributors MCS conceived the study question. MCS, PM and DP designed the study objectives and developed the study procedures. LT provided methodological and statistical support. MCS drafted the first version of the manuscript; and all authors read, provided comments and approved the final draft.

Competing interests None declared.

Ethics approval Hamilton Integrated Research Ethics Board.

Provenance and peer review Not commissioned; externally peer reviewed. 
Open Access This is an Open Access article distributed in accordance with the Creative Commons Attribution Non Commercial (CC BY-NC 4.0) license, which permits others to distribute, remix, adapt, build upon this work noncommercially, and license their derivative works on different terms, provided the original work is properly cited and the use is non-commercial. See: http:// creativecommons.org/licenses/by-nc/4.0/

\section{REFERENCES}

1. Soucacos PN, Zacharis K, Soultanis K, et al. Risk factors for idiopathic scoliosis: review of a 6-year prospective study. Orthopedics 2000;23:833-8.

2. Ueno M, Takaso M, Nakazawa T, et al. A 5-year epidemiological study on the prevalence rate of idiopathic scoliosis in Tokyo: school screening of more than 250,000 children. J Orthop Sci 2011;16:1-6.

3. Riseborough EJ, Wynne-Davies R. A genetic survey of idiopathic scoliosis in Boston, Massachusetts. J Bone Joint Surg Am 1973;55:974-82.

4. Misterska E, Glowacki M, Latuszewska J, et al. Perception of stress level, trunk appearance, body function and mental health in females with adolescent idiopathic scoliosis treated conservatively: a longitudinal analysis. Qual Life Res 2013;22:1633-45.

5. Théroux J, Le May S, Fortin $\mathrm{C}$, et al. Prevalence and management of back pain in adolescent idiopathic scoliosis patients: a retrospective study. Pain Res Manag 2015;20:153-7.

6. Danielsson AJ, Wiklund I, Pehrsson K, et al. Health-related quality of life in patients with adolescent idiopathic scoliosis: a matched follow-up at least 20 years after treatment with brace or surgery. Eur Spine J 2001;10:278-88.

7. Noshchenko A, Hoffecker L, Lindley EM, et al. Predictors of spine deformity progression in adolescent idiopathic scoliosis: a systematic review with meta-analysis. World J Orthop 2015;6:537.

8. Sun X, Wang B, Qiu Y, et al. Outcomes and predictors of brace treatment for girls with adolescent idiopathic scoliosis. Orthop Surg 2010;2:285-90.

9. Katz DE, Herring JA, Browne $\mathrm{RH}$, et al. Brace wear control of curve progression in adolescent idiopathic scoliosis. J Bone Joint Surg Am 2010;92:1343-52

10. Weinstein SL, Dolan LA, Wright JG, et al. Effects of bracing in adolescents with idiopathic scoliosis. N Engl J Med 2013;369:1512-21.

11. Nachemson AL, Peterson L-E. Effectiveness of treatment with a brace in girls who have adolescent idiopathic scoliosis. A prospective, controlled study based on data from the Brace Study of the Scoliosis Research Society. J Bone Joint Surg Am 1995;77:815-22.

12. Lonstein JE, Winter RB. The Milwaukee brace for the treatment of adolescent idiopathic scoliosis. A review of one thousand and twenty patients. J Bone Joint Surg Am 1994;76:1207-21.

13. Danielsson AJ, Hasserius $R$, Ohlin A, et al. A prospective study of brace treatment versus observation alone in adolescent idiopathic scoliosis: a follow-up mean of 16 years after maturity. Spine 2007;32:2198-207.

14. Goldberg CJ, Moore DP, Fogarty EE, et al. Adolescent idiopathic scoliosis: the effect of brace treatment on the incidence of surgery. Spine 2001;26:42-7.

15. Kim YJ, Lenke LG, Kim J, et al. Comparative analysis of pedicle screw versus hybrid instrumentation in posterior spinal fusion of adolescent idiopathic scoliosis. Spine 2006;31:291-8.

16. Merola AA, Haher TR, Brkaric M, et al. A multicenter study of the outcomes of the surgical treatment of adolescent idiopathic scoliosis using the Scoliosis Research Society (SRS) outcome instrument. Spine 2002;27:2046-51.

17. Betz RR, Harms J, Clements DH III, et al. Comparison of anterior and posterior instrumentation for correction of adolescent thoracic idiopathic scoliosis. Spine 1999;24:225-39.

18. Haher TR, Merola A, Zipnick RI, et al. Meta-analysis of surgical outcome in adolescent idiopathic scoliosis: a 35-year english literature review of 11,000 patients. Spine 1995;20:1575-84.

19. Coe JD, Arlet V, Donaldson W, et al. Complications in spinal fusion for adolescent idiopathic scoliosis in the new millennium. A report of the Scoliosis Research Society Morbidity and Mortality Committee. Spine 2006;31:345-9.

20. Asher MA, Burton DC. Adolescent idiopathic scoliosis: natura history and long term treatment effects. Scoliosis 2006;1:2.

21. Deguchi M, Kawakami N, Kanemura T, et al. Experimental scoliosis induced by rib resection in chickens. J Spinal Disord Tech 1995;8:179-85.
22. Ouellet $\mathrm{J}$, Odent T. Animal models for scoliosis research: state of the art, current concepts and future perspective applications. Eur Spine J 2013;22(Suppl 2):S81-95.

23. Burwell RG, Dangerfield PH, Moulton A, et al. Adolescent idiopathic scoliosis (AIS), environment, exposome and epigenetics: a molecular perspective of postnatal normal spinal growth and the etiopathogenesis of AIS with consideration of a network approach and possible implications for medical therapy. Scoliosis 2011;6:26.

24. Cheung KM, Wang T, Qiu GX, et al. Recent advances in the aetiology of adolescent idiopathic scoliosis. Int Orthop 2008;32:729-34

25. Gorman KF, Julien C, Moreau A. The genetic epidemiology of idiopathic scoliosis. Eur Spine J 2012;21:1905-19.

26. Kesling KL, Reinker KA. Scoliosis in twins. A meta-analysis of the literature and report of six cases. Spine 1997;22:2009-14; discussion 15

27. Andersen MO, Thomsen K, Kyvik KO. Adolescent idiopathic scoliosis in twins: a population-based survey. Spine 2007;32:927-30

28. Inoue $\mathrm{M}$, Minami $\mathrm{S}$, Kitahara $\mathrm{H}$, et al. Idiopathic scoliosis in twins studied by DNA fingerprinting: the incidence and type of scoliosis. $J$ Bone Joint Surg Br 1998;80:212-17.

29. Miller NH. Genetics of familial idiopathic scoliosis. Clin Orthop Relat Res 2007;462:6-10.

30. Grauers A, Rahman I, Gerdhem P. Heritability of scoliosis. Eur Spine J 2012;21:1069-74.

31. Raggio CL, Giampietro PF, Dobrin S, et al. A novel locus for adolescent idiopathic scoliosis on chromosome 12p. J Orthop Res 2009;27:1366-72.

32. Gurnett CA, Alaee F, Bowcock A, et al. Genetic linkage localizes an adolescent idiopathic scoliosis and pectus excavatum gene to chromosome 18 q. Spine 2009;34:E94-100.

33. Xu JF, Yang GH, Pan XH, et al. Association of GPR126 gene polymorphism with adolescent idiopathic scoliosis in Chinese populations. Genomics 2015;105:101-7.

34. Qiu XS, Lv F, Zhu ZZ, et al. Lack of association between the CHL1 gene and adolescent idiopathic scoliosis susceptibility in Han Chinese: a case-control study. BMC Musculoskelet Disord 2014;15:38.

35. Miyake A, Kou I, Takahashi Y, et al. Identification of a susceptibility locus for severe adolescent idiopathic scoliosis on chromosome 17q24.3. PLOS ONE 2013;8:e72802.

36. Kou I, Takahashi Y, Johnson TA, et al. Genetic variants in GPR126 are associated with adolescent idiopathic scoliosis. Nat Genet 2013;45:676-9.

37. Zhou S, Zhu Z, Qiu X, et al. Association study of IL-17RC, CHL1, DSCAM and CNTNAP2 genes polymorphisms with adolescent idiopathic scoliosis susceptibility in a Chinese Han population. Stud Health Technol Inform 2012;176:47-51.

38. Zhou S, Qiu XS, Zhu ZZ, et al. A single-nucleotide polymorphism rs708567 in the IL-17RC gene is associated with a susceptibility to and the curve severity of adolescent idiopathic scoliosis in a Chinese Han population: a case-control study. BMC Musculoskelet Disord 2012;13:181.

39. Qiu Y, Mao SH, Qian BP, et al. A promoter polymorphism of neurotrophin 3 gene is associated with curve severity and bracing effectiveness in adolescent idiopathic scoliosis. Spine 2012;37:127-33.

40. Mórocz M, Czibula Å, Grózer ZB, et al. Association study of BMP4, IL6, Leptin, MMP3, and MTNR1B gene promoter polymorphisms and adolescent idiopathic scoliosis. Spine 2011;36:E123-E30.

41. Liu Z, Tang NL, Cao XB, et al. Lack of association between the promoter polymorphisms of MMP-3 and IL- 6 genes and adolescent idiopathic scoliosis: a case-control study in a Chinese Han population. Spine 2010;35:1701-5.

42. Qiu XS, Tang NL, Yeung HY, et al. Melatonin receptor 1B (MTNR1B) gene polymorphism is associated with the occurrence of adolescent idiopathic scoliosis. Spine 2007;32:1748-53.

43. Cheng JC, Tang NL, Yeung HY, et al. Genetic association of complex traits: using idiopathic scoliosis as an example. Clin Orthop Relat Res 2007;462:38-44.

44. Ward K, Ogilvie J, Argyle V, et al. Polygenic inheritance of adolescent idiopathic scoliosis: a study of extended families in Utah. Am J Med Genet A 2010;152A:1178-88.

45. Londono D, Kou I, Johnson TA, et al. A meta-analysis identifies adolescent idiopathic scoliosis association with LBX1 locus in multiple ethnic groups. J Med Genet 2014;51:401-6.

46. Takahashi Y, Kou I, Takahashi A, et al. A genome-wide association study identifies common variants near LBX1 associated with adolescent idiopathic scoliosis. Nat Genet 2011;43:1237-40. 
47. Sharma S, Gao X, Londono D, et al. Genome-wide association studies of adolescent idiopathic scoliosis suggest candidate susceptibility genes. Hum Mol Genet 2011;20:1456-66.

48. Fernández-Jaén A, Suela J, Fernández-Mayoralas DM, et al. Microduplication 10q24.31 in a Spanish girl with scoliosis and myopathy: the critical role of LBX. Am J Med Genet $A$ 2014;164A:2074-8

49. Lu C, Thompson CB. Metabolic regulation of epigenetics. Cell Metab 2012;16:9-17.

50. Pinney SE, Simmons RA. Epigenetic mechanisms in the development of type 2 diabetes. Trends Endocrinol Metab 2010;21:223-9.

51. Lee WT, Cheung CS, Tse YK, et al. Generalized low bone mass of girls with adolescent idiopathic scoliosis is related to inadequate calcium intake and weight bearing physical activity in peripubertal period. Osteoporos Int 2005;16:1024-35.

52. Ramírez M, Martínez-Llorens J, Sanchez JF, et al. Body composition in adolescent idiopathic scoliosis. Eur Spine $J$ 2013;22:324-9.

53. Siu King Cheung C, Tak Keung Lee W, Kit Tse Y, et al. Abnormal peri-pubertal anthropometric measurements and growth pattern in adolescent idiopathic scoliosis: a study of 598 patients. Spine 2003;28:2152-7.

54. Wei-Jun W, Xu S, Zhi-Wei W, et al. Abnormal anthropometric measurements and growth pattern in male adolescent idiopathic scoliosis. Eur Spine J 2012:21:77-83.

55. Grivas TB, Vasiliadis E, Mouzakis V, et al. Association between adolescent idiopathic scoliosis prevalence and age at menarche in different geographic latitudes. Scoliosis 2006;1:9.

56. Hresko MT. Idiopathic scoliosis in adolescents. N Engl J Med 2013;368:834-41.

57. Holm VA, Laurnen EL. Prader-Willi syndrome and scoliosis. Dev Med Child Neurol 1981;23:192-201.

58. Hensinger RN, Lang JE, MACEWEN GD. Klippel-Feil syndrome. J Bone Joint Surg Am 1974;56:1246-53.

59. Isu $\mathrm{T}$, Chono $\mathrm{Y}$, Iwasaki $\mathrm{Y}$, et al. Scoliosis associated with syringomyelia presenting in children. Childs Nerv Syst 1992;8:97-100.

60. Geissele MAE, Kransdorf LMJ, Geyer MCA, et al. Magnetic resonance imaging of the brain stem in adolescent idiopathic scoliosis. Spine 1991;16:761-3.

61. Hankinson TC, Klimo P, Feldstein NA, et al. Chiari malformations, syringohydromyelia and scoliosis. Neurosurg Clin N Am 2007;18:549-68.

62. Arai $\mathrm{S}$, Ohtsuka $\mathrm{Y}$, Moriya $\mathrm{H}$, et al. Scoliosis associated with syringomyelia. Spine 1993;18:1591-2.

63. Dretakis EK. Brain-stem dysfunction and idiopathic scoliosis. Stud Health Technol Inform 2002;91:422-7.

64. Shi L, Wang D, Chu WC, et al. Automatic MRI segmentation and morphoanatomy analysis of the vestibular system in adolescent idiopathic scoliosis. Neuroimage 2011;54(Suppl 1): S180-8.

65. Guo X, Chau WW, Hui-Chan CW, et al. Balance control in adolescents with idiopathic scoliosis and disturbed somatosensory function. Spine 2006;31:E437-40.

66. Beaulieu M, Toulotte C, Gatto L, et al. Postural imbalance in non-treated adolescent idiopathic scoliosis at different periods of progression. Eur Spine J 2009;18:38-44.

67. Simoneau M, Mercier P, Blouin J, et al. Altered sensory-weighting mechanisms is observed in adolescents with idiopathic scoliosis. BMC Neurosci 2006;7:68.

68. Simoneau M, Richer N, Mercier P, et al. Sensory deprivation and balance control in idiopathic scoliosis adolescent. Exp Brain Res 2006;170:576-82.

69. Wiener-Vacher SR, Mazda K. Asymmetric otolith vestibulo-ocular responses in children with idiopathic scoliosis. J Pediatr 1998;132:1028-32.

70. Mahaudens P, Banse X, Mousny M, et al. Gait in adolescent idiopathic scoliosis: kinematics and electromyographic analysis. Eur Spine J 2009;18:512-21.

71. Cheung J, Halbertsma JP, Veldhuizen AG, et al. A preliminary study on electromyographic analysis of the paraspinal musculature in idiopathic scoliosis. Eur Spine J 2005;14:130-7.

72. Veldhuizen AG, Wever DJ, Webb PJ. The aetiology of idiopathic scoliosis: biomechanical and neuromuscular factors. Eur Spine $J$ 2000;9:178-84.

73. Dobosiewicz K. Neurophysiological mechanism of the unloading reflex as a prognostic factor in the early stages of idiopathic adolescent scoliosis. Eur Spine J 1997;6:93-7.

74. Smith RM, Dickson RA. Experimental structural scoliosis. J Bone Joint Surg Br 1987;69:576-81.
75. Wever DJ, Veldhuizen AG, Klein JP, et al. A biomechanical analysis of the vertebral and rib deformities in structural scoliosis. Eur Spine J 1999;8:252-60.

76. Ahl T, Albertsson-Wikland K, Kalén R. Twenty-four-hour growth hormone profiles in pubertal girls with idiopathic scoliosis. Spine 1988;13:139-42.

77. Willner S, Nilsson KO, Kastrup K, et al. Growth hormone and somatomedin A in girls with adolescent idiopathic scoliosis. Acta Paediatr Scand 1976;65:547-52.

78. Acaroglu E, Akel I, Alanay A, et al. Comparison of the melatonin and calmodulin in paravertebral muscle and platelets of patients with or without adolescent idiopathic scoliosis. Spine 2009;34: E659-63.

79. Nelson LM, Ward K, Ogilvie JW. Genetic variants in melatonin synthesis and signaling pathway are not associated with adolescent idiopathic scoliosis. Spine 2011;36:37-40.

80. Grivas TB, Savvidou OD. Melatonin the "light of night" in human biology and adolescent idiopathic scoliosis. Scoliosis 2007;2:1-14.

81. Girardo M, Bettini N, Dema E, et al. The role of melatonin in the pathogenesis of adolescent idiopathic scoliosis (AIS). Eur Spine J 2011;20:68-74.

82. Quu Y, Wu L, Wang B, et al. Asymmetric expression of melatonin receptor mRNA in bilateral paravertebral muscles in adolescent idiopathic scoliosis. Spine 2007;32:667-72.

83. Cheung KM, Lu DS, Poon AM, et al. Effect of melatonin suppression on scoliosis development in chickens by either constant light or surgical pinealectomy. Spine 2003;28:1941-4.

84. Qiu Y, Sun X, Qiu X, et al. Decreased circulating leptin level and its association with body and bone mass in girls with adolescent idiopathic scoliosis. Spine 2007;32:2703-10.

85. Liang G, Gao W, Liang A, et al. Normal leptin expression, lower adipogenic ability, decreased leptin receptor and hyposensitivity to leptin in adolescent idiopathic scoliosis. PLOS ONE 2012;7:e36648.

86. Liu Z, Tam EM, Sun GQ, et al. Abnormal leptin bioavailability in adolescent idiopathic scoliosis: an important new finding. Spine 2012;37:599-604.

87. Machida M, Dubousset J, Imamura $\mathrm{Y}$, et al. An experimental study in chickens for the pathogenesis of idiopathic scoliosis. Spine 1993;18:1609-15.

88. Machida M, Dubousset J, Imamura Y, et al. Pathogenesis of idiopathic scoliosis: SEPs in chicken with experimentally induced scoliosis and in patients with idiopathic scoliosis. J Pediatr Orthop 1994;14:329-35.

89. Machida M, Dubousset J, Imamura Y, et al. Role of melatonin deficiency in the development of scoliosis in pinealectomised chickens. J Bone Joint Surg Br 1995;77:134-8.

90. Machida M, Dubousset J, Imamura Y, et al. Melatonin. A possible role in pathogenesis of adolescent idiopathic scoliosis. Spine 1996;21:1147-52.

91. Bagnall KM, Raso VJ, Hill DL, et al. Melatonin levels in idiopathic scoliosis. Diurnal and nocturnal serum melatonin levels in girls with adolescent idiopathic scoliosis. Spine 1996;21:1974-8.

92. Cheung KM, Wang T, Poon AM, et al. The effect of pinealectomy on scoliosis development in young nonhuman primates. Spine 2005;30:2009-13.

93. Moreau A, Wang DS, Forget S, et al. Melatonin signaling dysfunction in adolescent idiopathic scoliosis. Spine 2004;29:1772-81.

94. Lombardi G, Akoume M-Y, Colombini A, et al. Biochemistry of adolescent idiopathic scoliosis. Adv Clin Chem 2011;54:165-82.

95. Burwell RG, Dangerfield PH, Moulton A, et al. Etiologic theories of idiopathic scoliosis: autonomic nervous system and the leptin-sympathetic nervous system concept for the pathogenesis of adolescent idiopathic scoliosis. Stud Health Technol Inform 2008;140:197-207.

96. Burwell RG, Aujla RK, Grevitt MP, et al. Pathogenesis of adolescent idiopathic scoliosis in girls-a double neuro-osseous theory involving disharmony between two nervous systems, somatic and autonomic expressed in the spine and trunk: possible dependency on sympathetic nervous system and hormones with implications for medical therapy. Scoliosis 2009;4:24.

97. Wang WJ, Yeung HY, Chu WC, et al. Top theories for the etiopathogenesis of adolescent idiopathic scoliosis. J Pediatr Orthop 2011;31(1 Suppl):S14-27.

98. Burwell RG, Dangerfield PH, Freeman BJ. Etiologic theories of idiopathic scoliosis. Somatic nervous system and the NOTOM escalator concept as one component in the pathogenesis of adolescent idiopathic scoliosis. Stud Health Technol Inform 2008;140:208-17.

99. Millner PA, Dickson RA. Idiopathic scoliosis: biomechanics and biology. Eur Spine J 1996;5:362-73. 
100. Mahood JK, Hull FR, Howell D, et al. The lateral profile in idiopathic scoliosis-a longitudinal cohort study. Orthop Trans 1990;14:724-5.

101. Roaf $R$. The treatment of progressive scoliosis by unilateral growth-arrest. J Bone Joint Surg Br 1963;45:637-51.

102. Dickson RA. Idiopathic scoliosis: foundation for physiological treatment. Ann R Coll Surg Engl 1987;69:89-96.

103. Spencer GSG, Eccles MJ. Spinal muscle in scoliosis: Part 2. The proportion and size of Type 1 and Type 2 skeletal muscle fibres measured using a computer-controlled microscope. J Neurol Sci 1976;30:143-54.

104. Fidler M, Jowett R. Muscle imbalance in the aetiology of scoliosis. $J$ Bone Joint Surg Br 1976;58:200-1.

105. Yarom R, Robin GC. Muscle pathology in idiopathic scoliosis. Isr J Med Sci 1979;15:917-24.

106. Yarom R, Robin GC. Studies on spinal and peripheral muscles from patients with scoliosis. Spine 1979;4:12-21.

107. Maffulli N. Histochemical and physiological studies in idiopathic scoliosis. Ital J Orthop Traumatol 1990;16:61-71.

108. Bylund $\mathrm{P}$, Jansson $\mathrm{E}$, Dahlberg $\mathrm{E}$, et al. Muscle fiber types in thoracic erector spinae muscles. Fiber types in idiopathic and other forms of scoliosis. Clin Orthop Relat Res 1987:222-8.

109. Khosla S, Tredwell SJ, Day B, et al. An ultrastructural study of multifidus muscle in progressive idiopathic scoliosis. Changes resulting from a sarcolemmal defect at the myotendinous junction. $J$ Neurol Sci 1980;46:13-31.

110. Dastych $\mathrm{M}$, Vlach O. Zinc status in patients with idiopathic scoliosis. Spine 1990;15:65-6.

111. Saartok T, Dahlberg E, Bylund $\mathrm{P}$, et al. Steroid hormone receptors, protein, and DNA in erector spinae muscle from scoliotic patients. Clin Orthop Relat Res 1984;183:197-207.

112. Gibson JNA, McMaster M, Scrimgeour $\mathrm{C}$, et al. Rates of muscle protein synthesis in paraspinal muscles: lateral disparity in children with idiopathic scoliosis. Clin Sci 1988;75:79-83.

113. Jansson E, Sylvén C, Bylund P. Myoglobin and enzyme adaptations in erector spinae muscles in thoracal scoliosis. Clin Physiol 1990;10:539-43.

114. Janssen MMA, de Wilde RF, Kouwenhoven JW, et al. Experimental animal models in scoliosis research: a review of the literature. Spine J 2011;11:347-58.

115. Wajchenberg M, Martins DE, Luciano Rde P, et al. Histochemical analysis of paraspinal rotator muscles from patients with adolescent idiopathic scoliosis: a cross-sectional study. Medicine (Baltimore) 2015;94:e598.

116. Tidball JG, Wehling-Henricks M. Shifts in macrophage cytokine production drive muscle fibrosis. Nat Med 2015;21:665-6.

117. Moyer AL, Wagner KR. Regeneration versus fibrosis in skeletal muscle. Curr Opin Rheumatol 2011;23:568-73.

118. Samaan MC. The macrophage at the intersection of immunity and metabolism in obesity. Diabetol Metab Syndr 2011;3:29.

119. Medzhitov R. Toll-like receptors and innate immunity. Nat Rev Immunol 2001;1:135-45.

120. Karagiannides I, Pothoulakis C. Obesity, innate immunity and gut inflammation. Curr Opin Gastroenterol 2007;23:661-6.

121. Hato T, Dagher PC. How the innate immune system senses trouble and causes trouble. Clin J Am Soc Nephrol 2015;10:1459-69

122. Mann CJ, Perdiguero E, Kharraz Y, et al. Aberrant repair and fibrosis development in skeletal muscle. Skelet Muscle 2011;1:21.

123. Murray PJ, Allen JE, Biswas SK, et al. Macrophage activation and polarization: nomenclature and experimental guidelines. Immunity 2014;41:14-20.

124. Samaan MC, Anand SS, Sharma AM, et al. Adiposity and immune-muscle crosstalk in South Asians \& Europeans: a cross-sectional study. Sci Rep 2015;5:14521.

125. Odegaard JI, Chawla A. Mechanisms of macrophage activation in obesity-induced insulin resistance. Nat Clin Pract Endocrinol Metab 2008;4:619-26.
126. Gordon S. Macrophage heterogeneity and tissue lipids. J Clin Invest 2007;117:89-93.

127. Gordon S, Taylor PR. Monocyte and macrophage heterogeneity. Nat Rev Immunol 2005;5:953-64.

128. Lemos DR, Babaeijandaghi F, Low $M$, et al. Nilotinib reduces muscle fibrosis in chronic muscle injury by promoting TNF-mediated apoptosis of fibro/adipogenic progenitors. Nat Med 2015;21:786-94.

129. Kawamura S, Ying L, Kim HJ, et al. Macrophages accumulate in the early phase of tendon-bone healing. J Orthop Res 2005;23:1425-32.

130. Rockett HR, Breitenbach M, Frazier AL, et al. Validation of a youth/ adolescent food frequency questionnaire. Prev Med 1997;26:808-16.

131. https://regepibwhharvardedu/health/KIDS/files/03 2012 Youth Adolescent Food Frequency Questionnairepdf (accessed 9 May 2013).

132. Merchant AT, Dehghan M, Behnke-Cook D, et al. Diet, physical activity, and adiposity in children in poor and rich neighbourhoods: a cross-sectional comparison. Nutr J 2007;6:1

133. Hay J, Cairney J. Development of the Habitual Activity Estimation Scale for clinical research: a systematic approach. Pediatr Exerc Sci 2006;18:193-202.

134. Chervin RD, Hedger K, Dillon JE, et al. Pediatric sleep questionnaire (PSQ): validity and reliability of scales for sleep-disordered breathing, snoring, sleepiness, and behavioral problems. Sleep Med 2000;1:21-32.

135. Faulstich ME, Carey MP, Ruggiero L, et al. Assessment of depression in childhood and adolescence: an evaluation of the Center for Epidemiological Studies Depression Scale for Children (CES-DC). Am J Psychiatry 1986;143:1024-7.

136. Brownson RC, Chang JJ, Eyler AA, et al. Measuring the environment for friendliness toward physical activity: a comparison of the reliability of 3 questionnaires. Am J Public Health 2004;94:473-83.

137. Coleman L, Coleman J. The measurement of puberty: a review. $J$ Adolesc 2002;25:535-50.

138. Samaan MC, Marcinko K, Sikkema S, et al. Endurance interval training in obese mice reduces muscle inflammation and macrophage content independently of weight loss. Physiol Rep 2014;2:e12012.

139. Samaan MC, Anand SS, Sharma AM, et al Sex differences in skeletal muscle Phosphatase and tensin homolog deleted on chromosome 10 (PTEN) levels: a cross-sectional study. Sci Rep 2015;5:9154

140. Chen X, Cho DB, Yang PC. Double staining immunohistochemistry. N Am J Med Sci 2010;2:241-5.

141. Krause MP, Moradi J, Nissar AA, et al. Inhibition of plasminogen activator inhibitor-1 restores skeletal muscle regeneration in untreated type 1 diabetic mice. Diabetes 2011;60:1964-72.

142. Arrighi N, Moratal C, Clément N, et al. Characterization of adipocytes derived from fibro/adipogenic progenitors resident in human skeletal muscle. Cell Death Dis 2015;6:e1733.

143. Genin M, Clement F, Fattaccioli A, et al. M1 and M2 macrophages derived from THP-1 cells differentially modulate the response of cancer cells to etoposide. BMC Cancer 2015;15:1-14.

144. Fernandez-Bueno I, Garcia-Gutierrez MT, Srivastava GK, et al. Adalimumab (tumor necrosis factor-blocker) reduces the expression of glial fibrillary acidic protein immunoreactivity increased by exogenous tumor necrosis factor alpha in an organotypic culture of porcine neuroretina. Mol Vis 2013;19:894-903.

145. King MD, Alleyne $\mathrm{CH}$, Jr, Dhandapani KM. TNF-alpha receptor antagonist, R-7050, improves neurological outcomes following intracerebral hemorrhage in mice. Neurosci Lett 2013;542:92-6.

146. Akhurst RJ, Hata A. Targeting the TGF[beta] signalling pathway in disease. Nat Rev Drug Discov 2012;11:790-811.

147. Norman GR, Streiner DL. PDQ statistics 2003. 3rd edn. 